\title{
The Burdens on Caregivers of Patients above 65 Years Old Receiving Hemodialysis: A Qualitative Study
}

\section{Alnazly EK ${ }^{1 *}$ and Samara NA ${ }^{2}$}

${ }^{1}$ Assistant Professor at Amman Alahliyya University / Nursing School, Amman, Jordan

${ }^{2}$ St. John's Hospital, Springfield, Illinois USA

\begin{abstract}
Background: End-stage renal failure is a chronic disease routinely treated with hemodialysis. Hemodialysis is the disease's only available treatment in Jordan; it is a life-long treatment that imposes burdens on patients and their caregivers. Most patients have unpaid family caregivers who do a variety of tasks and so become increasingly burdened, occupied with those tasks, and unable to participate in activities of interest to them.
\end{abstract}

Aim: The goal of this study is to explore the experience of caregivers of patients 65 years and older receiving hemodialysis in order to understand the burdens of this specific population.

Methods: The study subjects were the caregivers of patients who received outpatient hemodialysis at one outpatient hemodialysis center in the capital city of Amman, Jordan. A total number of nine caregivers were included in the study. The caregivers' ages ranged from 35 to 65 , averaging 50 years old, but the patients were above 65 years old. An interview guide with semi-structured questions and Colaizzi's strategy of descriptive phenomenological data analysis were used.

Result: The majority of caregiver subjects reported social isolation, health problems, and little time for self-care. Factors alleviating caregiver burdens included faith in God, participating in religious practices and venting of feelings.

Conclusions: Identification of caregiver burdens and of coping strategies should help healthcare professionals understand the caregivers' burdens and identify their needs by patients receiving hemodialysis to relieve their psychosocial and physical burdens.

Keywords: Hemodialysis; Burden; Caregiver; Colaizzi's method; Semi-structured interviews

\section{Introduction}

Dialysis is a lifelong treatment for end stage renal disease (ESRD) associated with physical and psychosocial challenges that affect not only the patients but also family members who care for them $[1,2]$. Caregivers help patients at home with many daily activities, including transportation to the dialysis centers, symptoms management, mobility, dressing, and preparing an appropriate renal diet [3]. Some studies have documented how caregivers' responses to the needs of chronically ill family members at home have adversely affected multiple aspects of their lives, including their stress level, family relationships and social lives in general [4]. The adverse consequences for caregiving also include the amount of time and effort they need to provide the caregiving recipient with psychosocial support, which includes coordination of care, illnessrelated financial management, mobility, and household tasks $[5,6]$.

The concept of "caregiver burden" has been used to identify the impact of caregiving on caregivers. Given et al. [7] defined this burden as "a multidimensional bio-psychosocial reaction that results from an imbalance of care demands relative to the caregivers' personal time, social roles, physical and emotional states, financial resources, and formal care resources given the other multiple roles they fulfill."

Like many Arabs and Muslims, Jordanian families provide care to chronically sick patients at home; the patient may move into the caregiver's house, or the caregiver may move into patient's house. This cultural practice has lately become more prevalent because there has been a rapid increase in the number of elderly persons with chronic conditions [8]. Al-Jauissy [9] stated that the Jordanian culture and traditions impose the sense of obligation and commitment to caring for the sick and / or the frail elderly. Al-Jauissy presented the commitment on three levels: "intentions", "verbal expression" and "actions". In Jordan, studies examining burdens for family members who are caregivers to patients receiving hemodialysis in general and above 65 year old particular that fully address the caregiver burden are insufficient. However, one recent study indicated that in Jordan the quality of life of hemodialysis-receiving patient and caregivers was lower than that for the general population [10]. Another study reported caregivers of stroke patient had high score of burden and depression [11]. To bridge the gap in knowledge of caregiver burdens, the purpose of the present qualitative study is to explore the experiences of caregivers of family members who are patients receiving hemodialysis, to better understand their burdens through the investigation of their lived experiences during the years of caregiving. The findings of this research can provide healthcare professionals with an understanding of the burdens among caregivers of patients receiving hemodialysis as well as to plan and implement strategies to help them cope with the burdens. For the purpose of this study caregiver is an unpaid individual who is related to the patient such as a spouse or a family member and involved in assisting patients with daily living activities and/or medical tasks.

*Corresponding author: Eman K Alnazly, Assistant Professor at Amman Alahliyya University / Nursing School, Amman, Jordan, Tel: + 9627950 97545; E-mail: emanalnazly@hotmail.com

Received January 10, 2014; Accepted February 06, 2014; Published February 08,2014

Citation: Alnazly EK, Samara NA (2014) The Burdens on Caregivers of Patients above 65 Years Old Receiving Hemodialysis: A Qualitative Study. Health Care Current Reviews 2: 118. doi: 10.4172/2375-4273.1000118

Copyright: (c) 2014 Alnazly EK, et al. This is an open-access article distributed under the terms of the Creative Commons Attribution License, which permits unrestricted use, distribution, and reproduction in any medium, provided the original author and source are credited. 


\section{Methods}

\section{Sampling and data collection}

Purposive sampling of nine caregivers from an outpatient hemodialysis unit of a large metropolitan hospital in Amman, Jordan, to explore the prospect of obtaining a comprehensive range of views from included caregivers with different relationships to the patients. Caregivers werea non-paid close family member (spouse, adult child, sibling, aunt, or uncle); patient is 65 and older, identified by the patient as the person who cares for the patient at home; at least 21 years old; able to read and write Arabic; currently caring for the patient and had been doing so for at least one year; and voluntarily willing to participate in the study.

The scientific committee of the participating hospital granted ethical approval for the study. Patients were informed of the study; once they agreed to have their caregiver participate; written consents to contact family caregivers were obtained. They were given a letter that indicated permission to be contacted to participate, along with a selfaddressed, stamped envelope. The letter was followed by a phone call one week later to confirm their consent to participate and to schedule the interview. Participants signed an informed consent and were told they could withdraw from the study at any time for any reason.

Because some caregiver do not come to dialysis units with patients, all of the interviews took place in the houses of the respective caregivers and in the absence of the patients to give the caregivers the chance to express their feelings as freely and plentifully as possible during the interviews. Semi-structured, face to face, guided interview were conducted. The interviews which were audio-taped often lasted between 45 and 60 minutes. Participants were encouraged to use their own words to tell their stories and talk freely. The interviews focused on the burdens experienced by family-member caregivers (Table 1). Participants were reminded of a second meeting a week later to discuss the study. The level of data saturation was determined by the two researchers.

\section{Sample size}

We invited all the caregivers who meet the criteria to participate in the study, and twelve caregivers agreed to participate. Although numerous books and chapters of qualitative research suggest that a sample size of 5 to 50 participants is adequate, saturation and redundancy were reached after the first researcher interviewed nine caregivers. In such qualitative studies, scholars argue that the concept of saturation is more important than thinking of sample size [12].

\section{Data analysis}

Descriptive phenomenological data analyses of Colaizzi's [1] seven steps were followed, including the following:

\begin{tabular}{|c|c|}
\hline No & Question \\
\hline 1 & $\begin{array}{l}\text { Please tell me about the changes in your life because } \\
\text { you have been a caregiver for the patient receiving } \\
\text { dialysis. }\end{array}$ \\
\hline 2 & $\begin{array}{l}\text { Tell me the effects of caregiving on your health } \\
\text { because you have been caring for the patient receiving } \\
\text { hemodialysis. }\end{array}$ \\
\hline 3 & Tell me how you coped with these stressors. \\
\hline 4 & $\begin{array}{l}\text { What kind of help do you feel you need that make the } \\
\text { caregiving task easier? }\end{array}$ \\
\hline 5 & $\begin{array}{l}\text { Clarification questions were asked, such as Tell me } \\
\text { more about that, What did you mean with that? How did } \\
\text { this happen? }\end{array}$ \\
\hline
\end{tabular}

Table 1: Qualitative request questionnaire.
1. The principal investigator read and reread each participant's transcript to obtain a general sense of the caregiver's lived experiences as a whole.

2. Each transcript was examined for statements and phrases that pertained to the phenomena under study; major statements were extracted from the descriptions, and these statements were recorded on a separate sheet.

3. Meanings were formulated from the significant statements.

4. The formulated meanings were sorted and then organized into categories, theme clusters, and themes to identify the experiences common to all participants.

5. The principal investigator integrated the themes into a comprehensive description of the lived experiences of the participants.

6. The researcher formulated a concise statement based on the exhaustive descriptions, which led to discovery of caregiver lived-experiences.

7. A final validation was sought from the research participants, which was achieved by meeting with them and asking if the descriptive analysis reflected their own experiences.

None of the participants disagreed with the descriptive analysis. A member of the research team reviewed and compared the transcripts, both to verify the emergent themes and confirm that the statements were based on transcribed study data rather than on the researcher's preconceptions.

\section{Results}

\section{Demographic characteristics}

The nine caregiver participants had an average age of 50 years, with a range from 35 to 65 years. The participants included 4 men and 5 women; their educational levels included 4 with a bachelor's degrees and 5 with a community college education; two caregivers were employed, one was single, eight were married, and three had children living in the house; the average time they had cared for the patients was 2.5 years.

\section{Qualitative data analysis}

Statements pertaining to caregiver burdens and coping strategies were extracted from the data. Six major themes came up: feelings of social isolation, overwhelmed by the responsibility, health decline, little time for self-care, coping responses, and needing additional support.

Feelings of social isolation: As a result of caring for patients' health problems, the participants frequently voiced the burden of social isolation from family and friends, with little or no time left to maintain friendships and get involved in social events. The worse the patient's health gets, the more the caregiver becomes isolated from his own social life. As the participant quoted above said, a man participant scarified his leisure time for caregiving, saying:

"I used to travel with my wife a lot. I enjoyed working on our little farm, but I can't do these activities anymore because she becomes so tired, and we found out she is getting more health problems. I stay with her at home in case she needs help; I am worried to leave her alone when I am not around.".. "I see her health deteriorating and she needs help with everything: walking and toileting; sometimes I have to feed her. I have no contacts with others and feel left alone." 
The caregivers without adequate family and social support often fall in the trap of isolation, increasing the risk of burden. Family conflicts make the isolation and the loneliness of caregivers worse. Another man caregiver said:

"Yes, my life has been socially isolated. Some of my relatives are difficult, so I stay away from them. Listen to this: My brother, who lives two doors down the street, wants me to move my wife into one of my children's' homes. ... I've been doing it for two years and there is not much time left for her to live."

Another woman, caring for her mother and two children, felt the house was a prison:

"Although I feel I am a prisoner at home. I am stuck at home to provide the best care I can possibly, I just want to be able to go out, living my normal social life, work, meet people, and see myself growing..."

Thus, caregivers providing care for family members suffer the burden of catering to their various daily needs. The causes of social isolation for caregivers appear to be diverse. They seem to include losing friendships and declining opportunities to attend social events; deterioration of the patients' health; family conflict; and feeling trapped and restrained caring for the patient.

Overwhelmed with the responsibility: When the countless caregiving responsibilities start to stack up faster than one is able to deal with them, the unpleasant response is the overwhelming feeling of too much responsibility and overburden. A man caregiver explains the overwhelming responsibility because of receiving little or no help from his siblings by saying:

"My mother has six boys, but they do not take part in her care. They come to visit and leave, all they do is say, 'How are you? Did you eat? You look good today; your son is doing a good job in taking care of you.' And then they leave. I moved my mother to my house to live with me and I gave up my job to take care of my mother because her health is getting worse. Now she cannot stand up and cannot turn herself in bed. I have to left her and put her in a wheelchair to set with us in the family room. She wakes up and does not know where she is or what time it is, and she keeps moaning and calling my name. We took her by ambulance to dialysis for the last three sessions but we skipped today's session. To say the truth, the main support my brothers give us is financial support."

Caregivers also take part in physical care, such as caring for wounds, bleeding and falls, with no previous experiences: A man caregiver said:

"You know, onetime I was driving my mother after dialysis; the dressing came off and started bleeding profusely from the needle stick. In a busy street I stopped the car by the roadside and put pressure on her arm. It never happened before and I didn't expect this and I was not prepared. Imagine, I was driving, my mother is bleeding, and you have to suddenly and quickly react and step into the first aid mode."

Burden is the symptom that stands out most on a daily basis, and it is not predictable. A participant caregiver said:

"Caregiving is an unpredictable task and you do not know what new issues that you may have to deal with and may come up from one day to the next. Such as if he is going to handle dialysis tomorrow, if the swelling will come down or be sick to his stomach, low blood count, fatigued and most of the time tired until the next day after dialysis. I just hope that I will do the right thing and hope that I am going to be alright. These issues are really hard on me as a caregiver. Onetime I was reading the news in Arabic on the internet and I flipped to English news; I start reading the English news from right to left. At that moment I realized that I am under stress."

Noteworthy, the youngest caregivers appear to have other commitments outside caring for their parents or spouses. They often have children and grandchildren at home. A mother of four children stated:

"It's like I have to do two jobs or more at one time. Any time you're doing something for someone else (I mean my other children) you have to stop and I have to respond to his need, such as going to the bathroom, or clean around him, or when he feels alone, he calls out 'Anybody around? Come and talk to me."

The caregivers' sleeping patterns get interrupted countless times by their care recipients; thus, they lack having a good-night's sleep, which can be impossible. In the mornings when they start their day, caregivers feel restless and exhausted. A woman participant said:

"When I sleep I do not feel I have rested enough because I know I have a lot to do the next day for him. I keep reminding myself with it, to look at the clock: Is it time to get up and start my day? And on top of that, by the time I close my eyes to rest he wakes up and needs something."

\section{Another woman participant said:}

"I am overwhelmed with the caregiving, and cannot say no to my husband, even though he understands that I am exhausted from the caregiving. Once in a while, I visit my daughter, so the only way I can do that is by taking him along with me. These infrequent visits make me happy but I still can't enjoy it because I still need to take care of him there, plus carry with me extra clothes for him, his own diet and medicines, I cannot say to my husband to stay at home today while I go and visit your daughter. It does not mean that I do not care about him, I am just tired and feel trapped with his care."

Health decline: Most of the caregivers reported that their personal health was getting worse because of the straining effect of caregiving. It was obvious that the worry, fatigue, pain, caregiving workload, and anxiety were the most common aspects of caregivers' declining health. They described the burden as wearing them out. A woman caregiver said:

"Taking care of my husband keeps me under constant stress because of the endless worrying. You know worrying is not good, it drains your energy, and always have a headache, body aches, terrible joints aches with minimal movements and these aches build up so I am always tired and get little sleep."

Burden emerged in various forms of physical illness, as may be seen from this statement.

"Although I take blood pressure medicine, I have been to the emergency room with sky-high blood pressure several times recently. My rheumatoid arthritis flares up often on a stressful day, my stomach is sore and I get nauseated, and sometimes I wake up with chills and sweating, as if I had bad dreams."

Other health issues associated with caregiving were physical injuries, because of pulling, rolling, lifting, and transporting patients. The emotional impact of caregiving depression and anxiety also surfaced as may be seen from this testimony:

"Yesterday, I brought my father from dialysis; he was so exhausted, on his way out of the car he fell on the driveway. I called my neighbor, 
he brought a blanket, rolled my father on it, and we carried him inside the house. My arms and hands are numb and my back hurts from the strain of lifting him. I cannot move my right shoulder, I have to keep it in a straight position, so I cannot provide care as I used to. I've been making frequent visits to the doctor's office.... "Watching my father's health deteriorating makes me very sad. I turn my head to the other side and cry. When I discussed this issue with my doctor, he put me on a mood pill.'

Caregiving for the dialysis patient created a tremendous burden on the caregiver's physical and psychosocial health, including depression and anxiety, which were very common among the participants. Observing a husband, wife or parent struggling with this chronic disease for many years and witnessing their health failing and weakening while caring for them is directly intertwined with the caregiver's physical and psychosocial health.

Little time for self-care: Caregiving has an impact on various aspects of the overall caregiver's well-being. When caring for patients' receiving hemodialysis, caregivers were not taking enough care of themselves. They dedicated their time to, among other things, coordinating caregiving activities with doctor's appointments, transportation to the dialysis unit, staying with the patient while receiving hemodialysis, and preparing the renal diet. This routine leaves the caregiver with little time for self-care. One 35-year-old man caregiver said:

"Many times I skip meals, or just put a bag of potato chips and munch on it. I do not have enough time to prepare my meal after an exhausting day. I do not get on the treadmill to exercise even though it is just a few steps away in front of the television. I do not get a good night's sleep; my father wakes up a lot during the night and the next day I am tired.". . "I feel my mind is occupied and my energy exhausted from the responsibility. Many times I forget to take my medicine. I keep postponing my personal stuff for later."

A sixty-four-year-old wife had a problem in keeping her doctor's appointment. Declining health imposed a burden on the caregiver who said:

"I am worried about my diabetes and high blood pressure. Most of the time I do not go to my doctor's appointment; I have to switch or rearrange my appointment several times to get in ... because something always comes up about his dialysis appointment or transportation that I have to cancel my own appointment and when I have time, I have nobody available to back me up or help me. And the worst part is I do not want to hurt her feelings and ask a friend to stay with my mother while I am away."

Sleeping habits have also been affected by caregiving, as noted in the following testimony:

"I don't sleep well. Dialysis appointments are at 06:00 so we have to be in the hospital at 5:30; so we wake up at 04:30 am because we live far from the nearest dialysis unit." ... "Three times a week I wake up early, take him to dialysis; after dialysis, I bring him home, then I go to work for eight hours. Roughly I get five hours of sleep."

Caregiver self-care including eating, sleeping, and health maintenance has been affected by caregiving. Sleeping habits are mostly reported as worse than before caregiving.

Coping responses: Religion was discussed as a means of coping with and adjusting to caregiving. Caregivers comfort themselves in their religious belief and in praying and meditating. Some caregivers feel positive about dialysis and fortunate to have it. Accepting caregiving responsibilities and giving up some personal leisure time for tasks are viewed as rewards from God. A caregiver said:

"As a caregiver, dialysis can be hard to cope with, but it's worth it to have my husband more days with us.... "My faith and religious teachings helped me to accept my husband's dependence on dialysis, although I miss my joy full time."... Anyway, it is worth the reward from God at the end.'

Caregivers might draw strength from their faith when faced with hemodialysis and when the symptoms of the chronic illness that overwhelmed them physically and psychosocially. When coping with illness and caregiver burdens, the use of religion and spirituality is no surprise because each participant in this group belongs to a faith.A man caregiver said:

"I believe in the power of prayers. I pray five times a day and recite verses from the holly book and without my faith, I couldn't have done this." ... "I'm thankful for the strength and peace God has given me."

Another coping strategy this group found helpful was venting their feelings. Most of the caregivers reported that they talked about their problems to others, which often made them feel better. A caregiver said:

"One of the most wonderful things that I have is my children. I rest my head on my son or daughter's shoulder and talk to them about the difficult day and sadness I had from A to Z ... I talk to a friend (she is also caregiver to her father) on the phone sometimes after everybody is sound asleep at night and we may talk for hours. She tells me how her father is doing and I tell her how my husband is doing. Ah, we sympathize, laugh about the goofy things and such; we vent and share those things."

Almost all caregivers in this study experienced burdens and sadness. Sharing their feelings with others and getting psychosocial support from friends eased their burdens.

Needing additional support: The psychosocial support caregivers needed was prominent. Without good psychosocial health, the caregiving task of managing and coordinating care such as the dialysis schedule, doctors' appointments, preparing meals, and providing a safe environment can lead to burdens. The participants explicitly indicated the need for psychosocial supports, as indicated in the following sentences:

"I need family support from my siblings. They usually come and go with minimal help. One day I asked for a day off to go to my granddaughter's graduation. My brother said he is too busy to take my father to dialysis... I am providing care to my mother alone. My mother an older lady, after dialysis, sleeps until the next day... I feel lonely; loneliness is killing me. My social life is almost nonexistent even with my mother present; I need someone to talk to."

House chores and providing activities of daily living are other burdens, especially for older and injured caregivers, as this 64-year-old woman stated:

"In the last three months I can tell my physical health is declining because I injured my back while assisting my husband out of the bed. Bath time and hygiene are the biggest challenges. Although my children help sometimes, I still need outside help. Another issue, we need some kind of training, maybe monthly, how caregivers can provide care for patients receiving hemodialysis, especially with sleeping problems, itching, food and fluid restriction, weakness, joint stiffening, how to deal with my husband's mood." 
The caregivers enunciated the need for education and training programs for caregiving tasks designated for this group of patients.

The additional supports that a number of caregivers felt were unavailable included transportation to the dialysis unit, someone to call for advice when needed, and an agency that provided respite care. A caregiver said:

"Transportation back and forth to dialysis unit is a hassle."..."We live on the top of the hill. Taxi drivers refuse to come up to the doorstep." Another participant suggested: "An agency that provides a nurse I could call to stay with my father when I visit the doctor." Another participant said: "It will be nice if someone teaches me how to do certain caregiving tasks, such as prepare meals for renal diet; teach me about chronic renal failure and alarming symptoms."

From a caregiver's perspective, the burden of providing care for the family member with ESRD is evident, and caregivers need help with burden relief, as indicated in the following statement:

"My family hired one part time helper, whom transports father to the dialysis unit and provide care at home while I am at work. $\mathrm{He}$ is always present in my mind. Simply being constantly aware of this situation is a source of stress, I am overwhelmed at times, and I don't know how others who are constant caregivers survive. I would suggest caregiver support group will be a top priority to keep caregiver sanity content."

Another caregiver stressed the overwhelming responsibility and financial burdens by saying:

"Although my father receives some retirement money, it is challenging juggling between my work, handling all finances, medication management, coordinating care and solving complicated issues. I am too stressed out psychosocially and physically. I really need stress relief help; it could be support group and social worker who can get involved with this."

Physicians and nurses can aid caregivers by identifying the level of burden and emphasizing the importance of maintaining caregiver's well-being and teaching effective self-care techniques to reduce caregiver burden. One participant said:

"My wife has been on hemodialysis for four years and I am getting older and weaker more than what I can handle ...never having a moment to my-self. Last time I visited the physician he did not even ask me 'how are you handling your wife with the caregiving?' or acknowledge my role as a caregiver. What I want to say to my physician or his nurse could help."

Assessing caregiver burdens, including psychosocial and physical health, and assisting with mobilizing elder care support networks are essential.

\section{Discussion}

The findings of this study give insight into the difficulties of providing adequate care for patients with a chronic disease such as ESRD. The facets that arose from our data analysis indicated that there was a considerable amount of psychosocial and physical burden that had an impact on various aspects of caregiver's well-being. Caregivers were found to be socially isolated, with their health deteriorating, overwhelmed with the responsibility, and having little time for selfcare as a result of caregiving. As evident from this qualitative study, our findings are consistent with those of Stenberg et al. [4] and Tong et al. [6], who identified signs and symptoms of caregiving burdens, which often include psychological problems in the form of psychosocial distress, anxiety, and depression. These signs are evidenced in these quotes: "I am worried," "left alone," "my life has been socially isolated," "sad," and "made me cry." Consequently, as a result, caregivers report physiological problems, such as fatigue, sleep disturbance, and a decline in their health, as evidenced in these quotes: "drains your energy; so tired and little sleep," and "sky-high blood pressure; my rheumatoid arthritis flares up." As a result, caregivers have multiple health-related problems that affect their physical functioning. Tong et al. [6] called these symptoms intrapersonal issues, which involve the psychosocial and physical impact of caregiving. Given the high level of burden that is associated with caregiving to patients receiving hemodialysis such as emotional and physical impacts, interventions to target those comorbidities as part of hemodialysis caregiving are still needed.

The theme of "social isolation" sums up the caregivers' feelings of distancing from the community, close relatives, and friends. Providing evidence-based research from other chronic illness studies, such as on cancer and dementia, often lack discussing social interaction and feeling isolated [13]. Caregivers of patients receiving hemodialysis in this study reported having to give up their social lifestyles including leisure time, vacations, relaxation activities, and social contact with friends and family and devoting that time to care for the recipient's needs and learning to perform caregiver tasks. However, with the burden of care, caregivers are most in need of the benefit of recuperating psychosocially and physically. What makes it more difficult is that they have the least amount of time and resources available to relieve themselves from caregiver duties. Furthermore, the theme "little time for self-care" reflects how caregivers were prioritizing the recipients' care and needs above their own, thus leading the caregiver to postpone satisfaction of their own needs, as evidenced in these statements: "I keep postponing my personal stuff for later;" and "I have to switch or rearrange my appointment." This situation leaves little time for maintaining good nutrition, enjoying leisure time, and following up with doctor's appointments.

Although this study is qualitative, the experience of caregivers in this study is comparable to those of other chronic illnesses, such as cancer, heart disease, dementia, and stroke. The literature review conducted by Goldberg and Rickler [14] concluded that the effect on caregivers across chronic illnesses were social, physical, and mental. Consistent with Glasdam et al. [15], the caregivers also experienced poor physical health, reported as headaches, high blood pressure, and back and joint pain.

Caregivers of patients receiving hemodialysis have a lot of responsibilities. They tend to the needs of the patient in addition to their own daily obligations. Additional support in various aspects of care provides some burden relief, such as through respite care and assistance with cleaning, personal care, grocery shopping, and transportation to the dialysis unit. Such support makes it possible for caregivers to receive help during the period when a time off from caregiving is needed [16]. Caregivers also need information support from healthcare professionals and other experienced staff. In contrast to health professionals, family caregivers do not have the skills to deal with the unknown circumstances that they encounter to meet the needs of those whom they care for. Holley and Mast [17] suggested this could be achieved in the form of conversations with a support group. Education and psychosocial intervention showed positive effects on the caregiver's well-being.

When the caregiver attempts to provide the best care, it may intensify the sense of burden. Under local Jordanian values, undertaking 
caregiving chores to sick and older relatives in the dire situations is regarded as praiseworthy uprightness, a godsend boon, and a chance for personal religious progression.

However, the majority of caregiver in this study reported psychosocial and physical burdens as a result of caregiving. This qualitative study concluded that Jordanian caregiver to patients receiving hemodialysis relied heavily on their religious beliefs to cope with the burdens of providing care. Prayer and trust in God as an effective coping strategy helped them get through the caregiving situation.

\section{Strengths and Limitations}

This study focused on data collected at a single point in time, asking caregivers to describe their experiences as caregivers including the process through which they found they encountered burdens. As perception of burden can change with time, longitudinal interviews across the course of caregiving are recommended to capture the experience trajectories of change. The lack of diversity in the sample might be another limitation worth considering. Also, the studied sample was small, obtained from one dialysis unit located in the capital city. Future research should include a broader range of participants with varied cultural backgrounds, including rural areas and small towns. Nevertheless, the study results suggest that the coping strategies that the caregivers employed improved their ability to make their caregiving experiences less burdensome.

Despite the current limitations of this qualitative study, we have presented relevant information that can be useful for closing the gap in the literature and safeguarding caregivers' well-being through clinical care provided to patients and their families. More research is recommended based on empirical data to investigate the level of burden among caregivers that reflects both their caregiving experiences and needs.

\section{Recommendation for the Nursing Professionals}

1. Empowering both patients and caregivers with adequate verbal and written information regarding the disease process, treatment procedure, complications expected after dialysis and how to deal with them, as well as the prognosis expected.

2. Updating caregivers of any changes in patient's health condition or treatment on regular basis.

3. Providing continuous education for any skills required to deal with possible emergencies at home such as cramps or bleeding from fistula site and giving emergency phone numbers as required.

4. Helping caregivers to identify social support persons or/and systems available to facilitate and coordinate regular guaranteed transportation of patients back and forth from dialysis units.

5. Nurse managers can advocate to include policies in the health care system that provide community support such as home visits and psychosocial counseling for caregivers of hemodialysis patients.

\section{Conclusion}

As the number of dialysis patients in Jordan increases, more family members' spouses and siblings will be involved in their care. For many caregivers, the impact of caregiving can often be significant especially for older patients. Caregiving can create enormous burdens on caregivers, who are trying to manage other aspects of their own lives. For this group managing caregiving tasks is demanding and creates physical and psychosocial burden; family caregivers often suffer a decline in physical and psychosocial health. A healthcare provider, for caregiver or for patients receiving hemodialysis older than 65 , needs to identify the burden level of caregivers and directly intervenes to reduce caregiver burden and improve caregiver's well-being.

\section{References}

1. Colaizzi P (1978) Psychological research as the phenomenologist's views it Oxford University Press, New York.

2. Low J, Smith G, Burns A, Jones L (2008) The impact of end-stage kidney disease (ESKD) on close persons: A Literature review. Clinical Kidney Journal 1: $67-79$.

3. Einollahi B, Taheri S, Nemati E, Abbaszadeh V, Nourbala MH (2009) Burden among care-giver of kidney transplant recipients and its associated factors. Saudi J Kidney Dis Transpl 20: 30-34

4. Stenberg U, Ruland CM, Miaskowski C (2010) Review of the literature on the effects of caring for a patient with cancer. Psych-Oncology 19: 1013-1025.

5. Gayomali C, Sutherland S, Finkelstein FO (2008) The challenge for the caregiver of the patient with chronic kidney disease. Nephrol Dial Transplant 23: 3749-3751

6. Tong A, Sainsbury P, Craig JC (2008) Support interventions for caregivers of people with chronic kidney disease: A systematic review. Nephrology Dialysis Transplantation 23: 3960-3965.

7. Given CW, Given B, Azzouze F, Kozachik S, Stommel M (2001) Predictors of pain and fatigue in the year following diagnosis among elderly cancer patients. J Pain Symptom Manage 21: 456-466.

8. Al-Heeti RM (2007) Why Nursing Home will not work: Caring for the needs of the aging Muslim American population. Elder Law Journal 15: 205-231.

9. Al-Jauissy MS (2010) Health care needs of Jordanian caregivers with cance receiving chemotherapy on an outpatient basis. Eastern Mediterranean Health Journal 16: 1091-1097.

10. Shdaifat EA, Abdul Manaf MR (2012) Quality of life of caregivers and patients undergoing haemodialysis at Ministry of Health, Jordan. International Journal of Applied Science and Technology 2: 75-85

11. Kamal AA, Bond AE, Froelicher SE (2012) Depression and caregiver burden experienced by caregivers of Jordanian patients with stroke. Int J Nurs Pract 18: $147-154$

12. Mason M (2010) Sample size and saturation in $\mathrm{PhD}$ studies using qualitative interviews. Forum: Qualitative Social Research.

13. Brodaty H, Donkin M (2009) Family caregivers of people with dementia. Dialogues Clin Neurosci 11: 217-228.

14. Goldberg A, Rickler KS (2011) The role of family caregivers for people with chronic illness. Medical and Health, Rhodlland 94: 41-42.

15. Glasdam S, Timm H, Vittrup R (2010) Support efforts for caregivers of chronically ill persons. Clin Nur Res 19: 233-265.

16. National Family Caregivers Association (2010) State by State Statistics.

17. Holley CK, Mast B (2009) The impact of anticipatory grief of caregiver burden in dementia caregivers. Gerontologist 49: 388-396. 